\title{
Effect of Different Environment and their Interactions on Growth and Yield of Tomato (Solanum lycopersicum L.) Cultivars
}

\author{
Mukesh Kumar ${ }^{1}$, J. C. Chandola ${ }^{2 *}$, Durvesh Kumar Singh ${ }^{1}$, \\ Dinesh Kumar Singh ${ }^{1}$ and Vijay Kumar ${ }^{2}$
}

${ }^{1}$ Department of Vegetable Science, GBPUA \& T., Pantnagar, U.S Nagar, Uttarakhand, India

${ }^{2}$ Subject Matter Specialist Horticulture (Fruit Science) \& Lab. Technician, Krishi Vigyan

Kendra, Saran, DRPCAU, Pusa, Samastipur, India

*Corresponding author

\begin{abstract}
A B S T R A C T
A field experiment was conducted at Vegetable Research Centre, G.B. Pant University of Agriculture and Technology Pantnagar, U.S. Nagar Uttarakhand, during winter season of 2016-17 to study performance in and outside of poly-house to find out the most suitable and best cultivar, environment and interactions for growth, yield and quality of tomato fruits. The experiment was laid out in factorial randomized block design (R.B.D.) with three replications. Each replication consisted of eight treatment combinations viz., two tomato cultivars i.e., Pant Poly-house Tomato-2 (V1) and Pant Poly-house Hybrid Tomato -1 (V2), four environments (viz., E4- poly-house + spray of 2, 4-D), E3 (open + spray of 2, 4-D ), E2 (poly-house without spray) and E1 (open field without spray). Foliar spray of 2, 4-D @ 5 ppm concentration was applied as whole plant spray at 30,45 and 60 days after transplanting of tomato seedlings. Results of investigation revealed that the cultivar V1 produced highest fruit yield which was $12.13 \%$ higher over V2. Among the environmental treatments, E4 produced 66.39, $78.64271 .39 \%$ higher fruit yield over treatment E3, E2, $\mathrm{E} 1$, respectively. Among the interactions, treatment V1E4 performed better for 10 characters whereas, V2E4 \& V2E3 were better for 3 characters, and treatment V1E2 only for one character as compared to rest of the interactions. The treatment V1E4 gave $37.75 \%$ higher fruit yield than V2E4 and $84.44 \%$ over treatment V2E3 and $119.67 \%$ over V1E2.On the other hand, V2E4 produced $42.09 \%$ higher over V2E2 and $266.52 \%$ higher fruit yield over V2E1.Treatment V2E4 gave 33.89\% higher over V2E3.
\end{abstract}

\section{Introduction}

Tomato (Solanum lycopersicum L.) is one of the most widely grown vegetable crops in the world including tropical, sub-tropical and temperate regions. It is one of the most important 'protective food' because of the presence of the vitamin $\mathrm{A}$ and $\mathrm{C}$, minerals and lycopene. It is a rich source of minerals particularly potassium. It also contains organic acids particularly citric acid and malic acid. Ascorbic acid content ranges from 16 to $75 \mathrm{mg}$ per $100 \mathrm{~g}$ of edible part. It occupied 774 thousand hectare area and having 
production of 18,732 thousand metric tons with the productivity of 24.20 tons per hectare. As per $3^{\text {rd }}$ estimate of 2016-17 tomato occupied an area of 799 thousand hectare and produce 19,542 thousand metric tons of fruits with the productivity of 24.46 tons per hectare. (N.H.B, 2015-16). The efforts are continuously being made by researchers to develop high yielding cultivars for growers. Although, number of cultivars available for cultivation in the country. But very less numbers of cultivars are recommended for poly-house cultivation. Recently two new cultivars such as PPT-2, PPHT-1 has been released at state level for commercial cultivation to the farmers of the country for poly-house cultivation by the Pantnagar Researchers. The poly-house cultivation has distinct advantages of quality, productivity and favourable market price to the growers. Plant growth regulators play an important role in vegetable production by improving fruit setting, size, reduce flower and fruit drop, number and weight in several crops. Plant growth regulators are also known as plant exogenous hormones and these are synthetic substances that are similar to natural plant hormones. They are used to regulate the growth of the plants and are important measure to enhance and ensure horticulture production. By the use of the plant growth regulators, the fruit set can be improved by delaying the abscission of the flowers.

\section{Materials and Methods}

A field experiment was conducted at GBPUA\&T., Pantnagar, $\left(29^{0} \mathrm{~N}, 79.3^{0} \mathrm{E}\right.$, $243.84 \mathrm{~m}$ MSL), U.S. Nagar Uttarakhand, during winter season of 2016-17to study performance in and outside of poly-house to find out the most suitable and best cultivar, environment and interactions for growth, yield and quality of tomato fruits. Two tomato cultivars i.e., Pant Poly-house tomato-2 and Pant poly-house hybrid tomato-1 were grown under both the environments such as open field as well as under poly-house conditions. The recommended cultural practices for the crop were followed in the experimental field such as irrigation, weeding and plant protection measures. The observations were recorded on five tagged plants from each treatment and in each replication for various vegetative and reproductive characters. The data were analysed according to the method of analysis for two factorial Randomized block design given by Snedecor and Cochran (1968). The significance of variance among the treatments was observed by applying Ftest and least critical difference (LSD) at 5\% level of significance was calculated to compare the mean values of treatments for all the characters under study.

\section{Results and Discussion}

\section{Plant height}

Significant differences were found between the cultivars, environments and their interactions for plant height (Table 1). The highest plant height was recorded in cultivar V1 $(116.48 \mathrm{~cm})$ than V2 $(112.36 \mathrm{~cm})$. It may be due to genetic constituent of the cultivar. These results are similar to the findings of Prasad and Prasad (1977) and Olaniyi et al., (2010), who had also found variable plant height in different cultivars due to the genetic behaviour of the cultivars. Among all the environments, highest value was recorded in treatment E2 $(173.66 \mathrm{~cm})$ followed by $\mathrm{E} 4$ $(157.15 \mathrm{~cm})$ and E1 $(64.03 \mathrm{~cm})$. Foliar application of 2, 4-D reduced the plant height in treatment E4 than E2. Similarly, Foliar application of 2, 4-D reduced the plant height in treatment E3 than E1 in open field condition. These results are similar to the findings of Rai et al., (2006) and Ahmad et al., (2010). In poly-house conditions, foliar spray of 2, 4-D significantly reduced the plant height in treatment E4 as compare to E2. It 
may be due to the congenial condition available in the poly-house and due to the nature of the herbicidal effect of 2, 4-D which reduced the height of the plants. The lowest plant height was found in treatment E3 (62.83 $\mathrm{cm})$. Interaction effect revealed that the maximum plant height was found in treatment V1E2 $(184.02 \mathrm{~cm})$ followed by V1E4 (168.03 $\mathrm{cm})$ and V2E2 $(163.30 \mathrm{~cm})$ as compare to other interactions. The maximum plant height may be because of the congenial condition available for the better growth in cultivar V1 in E2 as compare to V2E2. Minimum plant height was recorded in V1E1 $(55.73 \mathrm{~cm})$ may be due to open field conditions, where the low temperature as well as other factors involve for the suppression of the height of the plants.

\section{Number of branches per plant}

The data of number of branches per plant (Table 1) revealed that more number of branches per plant was recorded in cultivar V2 (4.83) than cultivar V1 (2.58).It may be due to the genetic constitution of the cultivar. These results are similar to the findings of Lal et al., (1991) and Ahmad et al., (2007) who had also reported variable performance of cultivars may be due to the genetic factor of the cultivars. Among all the environments, the highest value was recorded in treatment E3 (4.08) followed by E4 and E2. Foliar application of 2,4-D significantly increased the number of branches per plant in treatment E3 than E1 (in open field condition without 2,4-D spray). It may be because of the reduced plant height and increased the number of branches by application of 2,4-D. Thus, by the absorbance of the nutrients from soil as well as photosynthates, synthesized in the leaves moves towards the bud growth. Therefore, the branches increased in number by receiving the congenial conditions provided by the poly-house and with the combined response of poly-house as well as 2,4-D which improve the growth of the plant by reducing the height and increased the branches per plant by application of 2,4-D. These results are similar to the finding of Rai et al., (2006). They also found that application of 2,4-D significantly increased the number of branches per plant under open field condition, as well as in poly-house condition. The lowest value for this character was found in treatment E1 (3.43).Among the interactions, more number of branches was recorded in treatment V2E3 (5.27) followed by V2E4 and V2E2 as compare to other interactions. The minimum number of branches per plant was recorded in V1E2 (2.30) followed by V1E1 and V1E4 as compare to other interactions.

\section{Percent fruit setting}

Non-significant difference was found between cultivars and interactions, for this character but it were significant for environment (Table 1). However, highest value for percent fruit setting was recorded in cultivar V1 $(86.63 \%)$ than V2 (86.26\%). The cultivar V1 was superior than V2 may be due to the genetic constitution of the cultivar and varietal differences. These results are similar to the findings of Kanneh et al., (2017). Who had also reported variable response for fruit setting in cultivars of tomato. Among all the environments, the maximum value was recorded in E4 (90.31\%) followed by E2 and, E3. However, the table indicated that foliar spray of 2,4-D increased the percent fruit setting of tomato in treatment E3 $(86.20 \%)$ than E1. These results are in accordance with the findings of Rai et al., (2006). They also found that application of 2,4-D significantly increased fruit setting percentage in open field condition. In poly-house condition foliar spray of 2,4-D significantly increased percent fruit setting of tomato in E4 $(90.31 \%)$ as compare to E2.Similarly, the increased fruit set percentage of tomato fruits was also found in poly-house condition. It may be because of 
getting favourable temperature, sunlight and other favourable conditions. Therefore, more number of flowers were converted into fruits by proper pollination and fertilization in polyhouse along with 2,4-D spray. Minimum percent fruit setting was recorded in treatment E1 $(81.58 \%)$ in open field condition without spray of 2,4-D.The interactions, showed that the highest percent fruit setting was recorded in V2E4 (90.49\%) followed by V1E4 and V1E2 than rest of the interactions. The highest percent fruit setting in V2E4 in polyhouse along with 2,4-D spray have received favourable environment for better setting of the fruits by foliar application of auxin in the form of 2,4-D which provide better condition for higher setting in Solanaceous vegetables, as also reported by Mehta (1983). Who had also reported that application of exogenous spray of auxin improve the fruit setting in tomato, in Chilli (Singh, 1983). They reported that 2,4-D reduced the flower and fruit drop and increase the setting of the fruits. The lowest percent fruit setting was recorded in V1E1 (80.51\%) as compare to other interactions.

\section{Number of fruits per plant}

Significant effect of cultivars, environments and their interactions was observed on number of fruits per plant (Table 1). The highest number of fruits per plant was recorded in cultivar V1 (23.78) because of the genetic constitution of the cultivar. These results are similar with the findings of Kanneh et al., (2017). Among all the environments, the more number of fruits per plant was observed in E4 (29.47) followed by E2 and E3. The data indicated that foliar spray of 2, 4-D increased the number of fruits per plant in E3 than E1 in open field conditions. It may be due to increasing the fruit setting by application of 2, 4-D which reduces the flower drop and influenced the fruit setting per plant as also mentioned by Tiwari and
Singh (2014). These results are in accordance with the findings of Rai et al., (2006). Among the interactions, more number of fruits per plant was recorded in V1E4 (29.97) followed by V2E4 and V2E2 as compare to other interactions. It may be due to spray of 2, 4-D in open field where unfavourable conditions were received by both the cultivars, and due to unfavorable low temperature conditions in which plants do not received favorable environment for better settings of the fruits. It also indicated that cultivar V1 is more hardy than V2 for unfavourable conditions. On the other hand, both the cultivars V1 and V2 respond better in $\mathrm{E} 4$ environment due to availability of better and favorable conditions for higher fruit setting as well as for better development of the plant by application of 2 , 4-D in open field as well as in poly-house. The minimum number of fruits per plant was recorded in V2E1 (11.43) followed by V1E1 and V1E3. Rest of the interactions showed intermediate performance for this character.

\section{Weight of fruits per plant}

Weight of fruits per plant was also significantly influenced with by different environment and their interactions (Table 1). However, the highest value was noted in cultivar V1 (1751.17g) than cultivar V2 $(1561.57 \mathrm{~g})$. It may be because of the genetic behavior of the cultivar. These results are in accordance with the results of Kanneh et al., (2017). Who had also recorded variable performance for this character due to the genetic response of the cultivar. Among all the environments, the maximum value was recorded in E4 $(2,726.43 \mathrm{~g})$ followed by E3 and E2 than E1 (734.10 g). The data indicated that foliar spray of 2, 4-D increased the weight of fruits per plant in E3 than E1 in open field conditions. These results are in accordance with the findings of Raiet al., (2006).They found that application of 2, 4-D significantly increase weight of fruits per 
plant $(\mathrm{g})$ in open field condition. Similarly, in poly-house condition, foliar spray of 2, 4-D significantly increases the weight of fruits per plant in E4 as compare to E2 treatment. It may be because of that plants received better environment by application of 2, 4-D as well as poly-house, for this character and photosynthates are transferred from leaves to the fruit. The minimum fruit weight per plant was obtained in E1 (734.10 g/plant). It may be due to unfavorable condition during the fruit development stage. Among the interactions, the highest value for weight of fruits per plant was recorded in V1E4 (3, $159.33 \mathrm{~g})$ followed by V2E4 and V2E3 as compare to other interactions. The better performance was noted in V1E4 than V2E4 may be due to better and favorable responses of the environment received by the cultivars. The lowest fruits weight per plant was recorded in V2E1 (625.76 g).

Table.1 Response of environment and their interactions on growth and reproductive characters of different tomato cultivars

\begin{tabular}{|c|c|c|c|c|c|c|c|}
\hline $\begin{array}{l}\text { Treatments/ } \\
\text { characters }\end{array}$ & $\begin{array}{l}\text { Plant } \\
\text { height } \\
\text { (cm) }\end{array}$ & $\begin{array}{l}\text { Number of } \\
\text { branches }\end{array}$ & $\begin{array}{l}\% \\
\text { fruit } \\
\text { set }\end{array}$ & $\begin{array}{l}\text { Number } \\
\text { of fruits } \\
\text { per plant }\end{array}$ & $\begin{array}{l}\text { Weight of } \\
\text { fruits per } \\
\text { plant (g) }\end{array}$ & $\begin{array}{l}\text { Average } \\
\text { fruit } \\
\text { weight (g) }\end{array}$ & $\begin{array}{l}\text { Fruit } \\
\text { yield } \\
\text { (q/ha) }\end{array}$ \\
\hline V1 & 116.48 & 2.58 & 86.63 & 23.78 & 1751.14 & 69.94 & 648.52 \\
\hline V2 & 112.36 & 4.83 & 86.26 & 22.65 & 1561.59 & 66.87 & 578.37 \\
\hline $\operatorname{LSD}_{(0.05)}$ & 3.12 & 0.08 & NS & 0.26 & 123.42 & NS & 45.71 \\
\hline E1 & 64.03 & 3.43 & 81.59 & 14.90 & 734.10 & 50.30 & 271.89 \\
\hline E2 & 173.66 & 3.49 & 87.69 & 25.30 & 1526.16 & 60.36 & 565.26 \\
\hline E3 & 62.83 & 4.08 & 86.20 & 23.18 & 1638.60 & 70.67 & 606.85 \\
\hline E4 & 157.15 & 3.82 & 90.31 & 29.47 & 2726.71 & 92.27 & 1009.79 \\
\hline $\mathbf{L S D}_{(0.05)}$ & 4.47 & 0.12 & 4.23 & 0.37 & 174.55 & 5.27 & 64.65 \\
\hline V1E1 & 55.73 & 2.40 & 80.51 & 18.37 & 842.44 & 45.87 & 312.01 \\
\hline V1E2 & 184.02 & 2.30 & 89.47 & 23.60 & 1438.18 & 60.94 & 532.66 \\
\hline V1E3 & 58.13 & 2.90 & 86.40 & 23.17 & 1564.28 & 67.51 & 579.29 \\
\hline V1E4 & 168.03 & 2.73 & 90.14 & 29.97 & 3159.65 & 105.43 & 1170.12 \\
\hline V2E1 & 72.33 & 4.47 & 82.66 & 11.43 & 625.56 & 54.73 & 231.76 \\
\hline V2E2 & 163.30 & 4.68 & 85.90 & 27.00 & 1614.14 & 59.78 & 597.83 \\
\hline V2E3 & 67.53 & 5.27 & 86.01 & 23.20 & 1712.93 & 73.83 & 634.42 \\
\hline V2E4 & 146.27 & 4.90 & 90.49 & 28.97 & 2293.76 & 79.18 & 849.45 \\
\hline $\operatorname{LSD}_{(0.05)}$ & 6.33 & 0.17 & NS & 0.52 & 246.85 & 7.46 & 91.42 \\
\hline
\end{tabular}

\section{Average fruit weight}

Significant differences for environments and their interactions, whereas non-significant difference was recorded between cultivars for average fruit weight (Table 1). However, highest value was recorded in cultivar V1, may be due to the genetic constitution of the cultivar.
Similar results were also found by Biswas et al., (2015) who had reported variable performance for this character may be due to variable response of the different cultivar in different environments. Among all the environments, maximum value was recorded in treatment E4 $(92.27 \mathrm{~g})$ followed by E3 and E2.The data showed that foliar spray of $2,4-\mathrm{D}$ significantly 
increased the average fruit weight in E3 than E1 in open field condition. These results are in accordance with the findings of Mehta et al., (1989). They found that application of 2, 4-D significantly increased the average fruit weight (g) of tomato in open field condition, as well as in poly-house condition where 2, 4-D act as hormone which increase the synthesis of photosynthates that moves from the leaves towards the fruits as also reported by Singh (1979). The minimum value for this character was found in treatment E1 (50.30 g). Similarly, foliar spray of 2, 4-D significantly increased the average fruit weight $(\mathrm{g})$ of tomato in $\mathrm{E} 4$ as compare to E2 environment in poly-house condition. Among the interactions, the highest value was recorded in V1E4 (105.43 g) followed by V2E4 and V2E3. The minimum value for this character was recorded in V1E1 (45.87) followed by V2E1 and V2E2 as compare to the rest of the interactions. Minimum average weight of fruit was recorded in V1E1 and V2E1, may be due to low temperature in open field condition because the proper synthesis of carbohydrate was not occurred due to unfavourable abiotic stress.

Significant differences were observed between the cultivars, environments and their interactions for fruit yield of tomato (Table 1). The data indicated that highest value was recorded in cultivar V1 $(648.52 \mathrm{q} / \mathrm{ha})$ than cultivar V2. It produce $12.13 \%$ higher fruit yield over V2. The results of the present investigation are supported by Singh (1989) and Kanneh et al., (2017) who had also found higher fruit yield in their respective trials by receiving congenial and better conditions for growth and development of the fruits. The superiority of V1 may be due to the greater number and weight of fruits per plant, percent fruit setting, fruit diameter, average fruit weight which ultimately increased the total fruit yield. The cultivars received better environment in open as well as in poly-house condition. Among all the environments, highest fruit yield was recorded in E4 (1009.79 q/ha) followed by E3 and E2. Treatment E4 produced $66.40 \%$ higher fruit yield over $\mathrm{E} 3$, and treatment $\mathrm{E} 4$ gave
$271.40 \%$ higher fruit yield over E1 while, treatment E3 produced $7.36 \%$ higher over E2. Foliar spray of 2, 4-D increased the fruit yield of tomato in E3 (606.85 q/ha) than E1 in open field conditions which was $123.19 \%$ higher than E1 (without 2, 4-D spray). The results are similar to the results of Singh (1986-87). They found that application of 2, 4-D significantly increased the fruit yield of tomato in open field condition. Similarly, under poly-house condition, foliar spray of 2, 4-D significantly increased the fruit yield of tomato in E4 as compare to E2 environment which was $78.64 \%$ higher over E2 under poly-house without spray. The higher yield in E4 may be due to receiving better condition for growth and development of the fruits and receiving higher uptake of nutrient from the soil by application of 2, 4-D which increase the fruit setting percentage, number of flowers per cluster, number of fruits per cluster, number and weight of fruits per plant, fruit diameter and the photosynthates manufactured in leaves directly moves from leaves towards the fruit which increase the fruit size, average fruit weight as well as number and weight of fruits per plant. The increased fruit yield of tomato was also found in poly-house condition may be due to the receiving congenial and favourable response by 2, 4-D as well as poly-house conditions. The minimum fruit yield was noted in treatment E1 (271.89 q/ha). Among the interactions, greater fruit yield was recorded in V1E4 (1170.12 q/ha) followed by V2E4 and V2E3 than rest of the interactions. The treatment V1E4 produced $37.75 \%$ higher fruit yield over V2E4, and $84.44 \%$ over V2E3, and V2E4 produced $33.89 \%$ higher over V2E3. The treatment V2E3 gave $173.74 \%$ higher over V2E1. Treatment V1E3 (579.29 q/ha) gave $85.66 \%$ higher fruit yield over V1E1. Treatment V1E4 produced $275.03 \%$ greater fruit yield over V1E1 and V2E4 produced $266.54 \%$ higher over V2E1, respectively. The higher yield in V1E4 may be due to the higher response of 2, 4-D along with the poly-house condition for better growth and development of the fruits as well as higher setting and due to more number and weight of fruits in this treatment. The minimum fruit yield was recorded in V2E1 
(231.76 q/ha) followed by V1E1 (312.01 q/ha) as compared to other interactions. It may be due to varietal variation in open field without spray of 2, 4-D.

\section{Acknowledgement}

It is proud privilege to express my most sincere and profound sense of gratitude to my advisor and chairman of my advisory committee Dr. Durvesh Kumar Singh, Department of vegetable Science, GBPUA\&T Pantnagar, Uttarakhand for his inspiring, nobel guidance, untiring help, keen interest, constant painstaking efforts, constructive criticism, constant encouragement and in carrying out the research and preparation of this manuscript also for providing necessary facilities to carry out the research work in an effective manner, which has made orientation of this memory of my life.

\section{References}

Anonymus. 2016. NHB, Gurgaon, Harayana India. $4 \mathrm{p}$.

Ahmad, F., Khan, O., Sarwar, S., Hussain, A. and Ahmad, S. 2007. Performance of tomato cultivars at high altitude. Sarhad J. Agric., 23(3).

Biswas, M., Sarkar, D. R., Asif, M. I., Sikder, S. K., Mehraj, H. and Jamal Uddin, A. F. M. 2015. Comparison of Growth and Yield Characteristics of BARI Tomato Varieties. Journal of Bioscience and Agriculture Research, 03(01): 01-7.

Kanneh, S. M., Quee, D. D., Ngegba, P. M. and Musa, P. D. 2017. Evaluation of Tomato (Solanum lycopersicum L.) Genotypes for Horticultural Characteristics on the
Upland in Southern Sierra Leone. Journal of Agricultural Science; 9(6).

Lal, G., Singh, D. K. and Tiwari, R. P. 1991. Performance of some tomato cultivars during summer in Tarai Region, Veg. Sci. 18(1): 99-101.

Mehta, A. K. 1983. Effect of concentrations and methods of application of 2, 4Dichlorophenoxy acetic acid on growth, yield and quality of tomato. (Lycopersicum esculentum Mill.) Ph.D thesis submitted to GBPUAT Pantnagar.

Mehta, A. K., Singh, R. P. and Lal, G. 1989. Effect of concentrations and methods of application of 2, 4-dichlorophenoxy acetic acid on yield, fruit quality and seed quality of tomato. Vegetable Science. 16(1): $1-8$.

Olaniyi, J. O.; Akanbi, W. B.; Adejumo T. A. and Akande, O. G. 2010. Growth, fruit yield and nutritional quality of tomato varieties. African Journal of Food Science, 4(6): 398-402.

Prasad, A. and Prasad, R. 1977. Studies on varietal performance of tomato. Prog. Hort. 9(2):58.

Rai, N., Yadav, D. S., Patel, K. K., Yadav, R. K., Asati, B. S. and Chaubey, T. 2006. Effect of plant growth regulators on growth yield and quality of tomato (Solanum lycopersicum Mill.) grown under mid hill of Meghalaya. Veg. Sci. 33(2): 180-182.

Tiwari, A. K. and Singh, D. K. 2014. Use of Plant Growth Regulators in Tomato (Solanum lycopersicum L.) under Tarai Conditions of Uttar hand. Indian Journal of Hill Farming, 27(2): 38-40.

\section{How to cite this article:}

Mukesh Kumar, J. C. Chandola, Durvesh Kumar Singh, Dinesh Kumar Singh and Vijay Kumar. 2020. Effect of Different Environment and their Interactions on Growth and Yield of Tomato (Solanum lycopersicum L.) Cultivars. Int.J.Curr.Microbiol.App.Sci. 9(10): 1796-1802. doi: https://doi.org/10.20546/ijcmas.2020.910.218 